\title{
Advances in development of fluorescent probes for detecting amyloid- $\beta$ aggregates
}

\author{
Ming-ming $\mathrm{XU}^{1, \#}$, Wen-ming REN ${ }^{2, \#}, \mathrm{Xi}_{\text {-can }} \mathrm{TANG}^{1}$, You-hong $\mathrm{HU}^{2,}{ }^{*}$, Hai-yan ZHANG ${ }^{1, *}$ \\ ${ }^{1}$ CAS Key Laboratory of Receptor Research, Shanghai Institute of Materia Medica, Chinese Academy of Science, Shanghai 201203, \\ China; 'State Key Laboratory of Drug Research, Shanghai Institute of Materia Medica, Chinese Academy of Sciences, Shanghai \\ 201203, China
}

\begin{abstract}
With accumulating evidence suggesting that amyloid- $\beta(A \beta)$ deposition is a good diagnostic biomarker for Alzheimer's disease (AD), the discovery of active $A \beta$ probes has become an active area of research. Among the existing imaging methods, optical imaging targeting $A \beta$ aggregates (fibrils or oligomers), especially using near-infrared (NIR) fluorescent probes, is increasingly recognized as a promising approach for the early diagnosis of AD due to its real time detection, low cost, lack of radioactive exposure and high-resolution. In the past decade, a variety of fluorescent probes have been developed and tested for efficiency in vitro, and several probes have shown efficacy in AD transgenic mice. This review classifies these representative probes based on their chemical structures and functional modes (dominant solvent-dependent mode and a novel solvent-independent mode). Moreover, the pharmaceutical characteristics of these representative probes are summarized and discussed. This review provides important perspectives for the future development of novel NIR A $\beta$ diagnostic probes.
\end{abstract}

Keywords: Alzheimer's disease; diagnostic biomarker; amyloid- $\beta$; optical imaging; near-infrared fluorescent probes

Acta Pharmacologica Sinica (2016) 37: 719-730; doi: 10.1038/aps.2015.155; published online 21 Mar 2016

\section{Introduction}

Alzheimer's disease (AD) is a devastating and progressive neurodegenerative disease that leads to progressive cognitive decline, functional impairment and loss of independence; thus, AD represents a significant and increasing clinical challenge ${ }^{[1-3]}$. $A D$ is characterized by two main hallmarks in the brain: the extracellular deposition of the amyloid- $\beta(A \beta)$ in senile plaques and the appearance of intracellular neurofibrillary tangles (NFTs) consisting of hyperphosphorylated tau protein $^{[2]}$. Today, more than 35 million people worldwide live with dementia and this number is expected to be more than triple to 115 million by $2050^{[3]}$. The heavy social costs and caregiving burden of AD have raised the attention for increasing research and potential therapeutics. However, the pathological mechanism of AD is elusive, and currently Food and Drug Administration (FDA)-approved medications, including four acetylcholinesterase inhibitors and one $N$-methyl- $D$-aspartate receptor (NMDA) receptor antagonist, only provide temporary

\footnotetext{
\# These authors contributed equally to this work.

* To whom correspondence should be addressed.

E-mail hzhang@simm.ac.cn (Hai-yan ZHANG); yhhu@simm.ac.cn (You-hong HU)

Received 2015-09-15 Accepted 2015-12-25
}

relief from symptoms. Additionally, none of these treatments halts the progression of this terminal disease. Therefore, early diagnosis seems to be a hopeful and promising approach to further the understanding and clinical treatment of this disorder. Currently, memory and behavioral tests are widely used for late-stage AD diagnosis ${ }^{[4]}$, and a definitive diagnosis is achieved only by postmortem examination to show the presence of $A \beta$ plaques and NFTs. Early-stage and asymptomatic diagnoses remain a challenge.

As a widely studied pathological hallmark of $A D$, the aggregation of fragmented $A \beta$ proteins into $A \beta$ plaques is closely connected with AD pathogenesis. Many risk factors in sporadic AD are associated with $A \beta$ metabolism, and mutations of $A \beta$-related genes in familial AD lead directly to AD pathogenesis ${ }^{[5-19]}$. Clinical research ${ }^{[20-25]}$ supports the hypothesis that there is a lengthy temporal lag between the appearance of $A \beta$ plaques and the emergence of clinical symptoms. Sperling et al ${ }^{[26]}$ proposed a biomarker model of the preclinical stage of AD in which $A \beta$ accumulation first becomes abnormal and a substantial $A \beta$ load accumulates before the appearance of clinical symptoms. As a consequence, the process of $A \beta$ plaque formation, namely $A \beta$ accumulation, has attracted growing attention as an important biomarker for early AD diagnosis. Moreover, Bruggink et al ${ }^{[27]}$ 
recently discovered an age-dependent $A \beta$ oligomer increase in the cortex and hippocampus of transgenic mice (APP/PS1) along with elevated levels of soluble $A \beta$ oligomers in human AD brain tissue compared with controls. Therefore, increasing evidence suggests that $A \beta$ oligomers are the proximal toxicant forms underlying the AD pathogenesis that eventually leading to cognitive and behavioral disorders. Central A $\beta$ oligomers, rather than $A \beta$ plaques, are predicted to be a better potential marker for early AD diagnosis.

Based on the role of $\mathrm{A} \beta$ accumulation in $\mathrm{AD}$ diagnosis, the past decade has seen great progress in the development of imaging probes for the non-invasive detection of $A \beta$, mainly relying on techniques such as positron emission tomography (PET), single-photon emission computed tomography (SPECT) and magnetic resonance imaging $(\mathrm{MRI})^{[28,29]}$. In particular, several PET probes have shown efficacy for imaging $A \beta$ in $A D$ brains. Among them, Florbetapir $\left({ }^{18} \mathrm{~F}\right)^{[30,31]}$ was launched by Lily in 2012 and Flutemetamol $\left({ }^{18} \mathrm{~F}\right)^{[32,33]}$ was launched by GE Healthcare in 2014. However, factors such as low sensitivity of MRI probes, high cost, narrow isotope availability, the shortlived isotopes of PET probes and the radioactivity of SPECT probes have restricted their clinical use. Currently, clinically available PET imaging requires expensive instruments, highly skilled personnel, time-consuming data analysis and unavoidable radiation exposure. The cost of one PET examination is approximately $\$ 1000$, which is a relatively high burden for the average family in developing countries.

Therefore, alternative technologies that are relatively inexpensive and easily applicable have recently attracted increasing attention. Optical imaging, especially near-infrared fluorescence (NIRF) imaging, when compared to PET, SPECT and MRI, is highly promising because it is real-time, inexpensive, not radioactive and of high-resolution both in vivo and ex vivo ${ }^{[34]}$. Additionally, unlike PET, NIRF imaging instrument costs are much lower, the data analysis takes less time, and highly skilled personnel are not needed. Optical imaging is an imaging technique using visible, ultraviolet, and infrared light for imaging. In particular, NIRF probes are favorable for $\mathrm{A} \beta$ detection in vivo because emission wavelengths in the NIR range (650-900 $\mathrm{nm}$ ) are distinct from the autofluorescence of biological matter, which is especially suitable for in vivo applications. During the last decade, a variety of $A \beta$ fluorescent probes have been developed and used to detect $A \beta$ in vitro and in vivo. The current trend in technical developments indicates that $A \beta$ fluorescence imaging is a potentially applicable technique that in the future could be feasible and widely used clinically.

\section{What makes an ideal $A \boldsymbol{\beta}$ fluorescent probe?}

In principle, an ideal fluorescent probe for $A \beta$ should have the following properties ${ }^{[35-38]}$ : (1) a high selectivity and a binding affinity for $\mathrm{A} \beta$; (2) a high quantum yield and a significant change in fluorescence upon binding to $A \beta$; (3) a suitable emission wavelength greater than $450 \mathrm{~nm}$ to minimize background fluorescence from brain tissue, ideally between $650 \mathrm{~nm}$ and $900 \mathrm{~nm}$ for in vivo detection; (4) the ability to rapidly cross the blood-brain barrier (BBB); (5) a high metabolic stability; (6) fast washout kinetics from normal brain regions; (7) low toxicity; and (8) straightforward synthesis.

\section{$A \beta$ fluorescent probes with classical push-pull architecture} In general, the emission spectra and quantum yield of fluorophores are profoundly influenced by the environment and the solvent used ${ }^{[39]}$, especially the solvent polarity ${ }^{[40]}$. Most fluorophores are polar molecules, which contain both an electrondonating and an electron-accepting group ${ }^{[41,42]}$ and usually display a large sensitivity to solvent polarity. Typically, fluorophores have a larger dipole moment in the excited state than in the ground state. The polar solvent can be more relaxed around the excited state than the ground state, which lowers the energy of the excited state $\mathrm{e}^{[43-45]}$. The above-mentioned solvent effects are used to determine any probe-macromolecule interactions. When the fluorophore binds to the macromolecule, the emission spectra or quantum yields change after dissolution in solvents of different polarity ${ }^{[46-48]}$.

The existing $A \beta$ fluorescent probes largely share a common structure, the classical push-pull architecture with terminal electron donor and acceptor moieties that are interconnected by a highly polarizable bridge. These probes are highly sensitive to solvent polarity and are essentially nonfluorescent in aqueous solutions, but highly fluorescent in nonpolar solvents or when bound to $A \beta$. In the following section, we introduce the different scaffold features of this mode.

\section{Thioflavin-T and its derivatives}

First introduced in 1959, the fluorescent dye thioflavin-T (ThT) (Figure 1, 1) has become a widely used "gold standard" for selectively staining and identifying amyloid fibrils both in vivo and in vitro ${ }^{[49]}$. When bound to amyloid fibrils, 1 shows enhanced fluorescence and a characteristic red-shift of the excitation and emission maxima from 350 and $438 \mathrm{~nm}$ to 450 and $482 \mathrm{~nm}^{[50]}$. The molecule of 1 consists of a benzothiazole (acceptor) and a benzylamine ring (donor) freely rotating around a shared $\mathrm{C}-\mathrm{C}$ bond (bridge). The hindrance in free rotation of the acceptor and donor is thought to suppress quenching and result in a high quantum yield of fluorescence when bound to $A \beta$, which is rich in $\beta$-sheet structures ${ }^{[51]}$. However, due to its charge and an emission wavelength less than $650 \mathrm{~nm}$, the in vivo usage of $\mathbf{1}$ is limited. A variety of derivatives of $\mathbf{1}$ have been developed. Although many of these derivatives are radiolabeled for PET/SPECT imaging, there are some fluorescent probes that show high affinity for $\mathrm{A} \beta$ aggregates in vitro.

Compound 12a (2) is a benzothiazole Schiff-base and has a high affinity for $\mathrm{AD}$ brain homogenates with a $K_{\mathrm{i}}$ value of $4.38 \mathrm{nmol} / \mathrm{L}$. This compound can label senile plaques, as confirmed by staining with thioflavin-S (ThS) in adjacent sections of $\mathrm{AD}$ brain tissue ${ }^{[52]}$. Jung et al designed and synthesized a series of ThT analogs. One of these analogs, compound 2 (3), showed high affinity for $A \beta$ fibrils $\left(K_{d}=3.27 \mu \mathrm{mol} / \mathrm{L}\right)$, a significant fluorescence increase $\left(F_{\mathrm{A} \beta} / F_{0}=36.1\right)$ and a $\log P$ value (3.7) suitable for potential BBB penetration. 3 was able to stain 


\section{Acceptor donor}

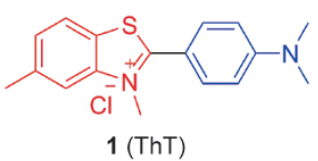

(PP-BTA-1)

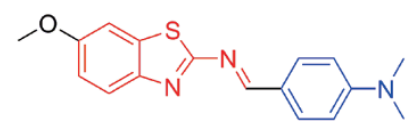

2

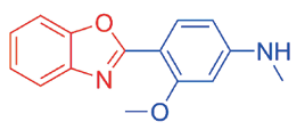

3<smiles>CN(C)c1ccc2nc(/C=C/c3ccc(/C=C(/[Pb])C#N)cc3)sc2c1</smiles>

Figure 1. Thioflavin-T and its derivatives.

intracellularly aggregated $A \beta$ fibrils in cultured cells ${ }^{[53]}$. However, the fluorescence spectra of the two above-mentioned probes are still in a range that limits their potential use in vivo.

Ono et al synthesized two push-pull benzothiazole derivatives (PP-BTA-1 (4) and PP-BTA-2 (5)) with either benzothiazole or styrylbenzothiazole as the highly polarized bridge, a dimethylamino group as the donor and a dicyanomethylene group as the acceptor. When exposed to $A \beta$ aggregates, the fluorescence intensity of $\mathbf{4}$ and $\mathbf{5}$ increased with increasing concentrations of $A \beta$ aggregates. Results of inhibition assays on the binding to $A \beta$ aggregates indicated that 4 and 5 may occupy a binding site on $\mathrm{A} \beta$ aggregates similar to that of $\mathbf{1}$. Meanwhile, the apparent $\mathrm{IC}_{50}$ values for 4 and 5 were 0.12 and $0.11 \mu \mathrm{mol} / \mathrm{L}$, respectively, indicating a high binding affinity for $A \beta$ aggregates. 4 and 5 clearly stained $A \beta$ plaques in brain sections of both transgenic mice and human AD patients ${ }^{[54]}$. Because the maximal emission wavelengths of $\mathbf{4}$ and $\mathbf{5}$ are approximately $600 \mathrm{~nm}$ and $550 \mathrm{~nm}$, respectively, further red -shifting of the emission wavelengths is necessary before these two probes are applicable for in vivo $\mathrm{A} \beta$ imaging.

\section{Derivatives of stilbene}

Stilbene is a hydrocarbon consisting of a trans ethene double bond substituted with phenyl groups on each carbon atom of the double bond. This structure was introduced because it is half of Chrysamine-G, which is a very close analog of Congo red, one of the most used compounds for staining $A \beta$ plaques in brain slices ${ }^{[55]}$.

The double bond in stilbene is the bridge connecting the electron donor and acceptor. Stilbene derivatives constitute a large family of radiolabeled $\mathrm{A} \beta$ probes. Based on the PET imaging probe SB-13, Hong et al synthesized 32 stilbene derivatives. Among them, compound 42 (Figure 2, 6) showed high fluorescence responsiveness $\left(F_{\mathrm{A} \beta} / F_{0}>25\right.$-fold $)$ and a strong binding affinity $\left(K_{d}=1.13 \mu \mathrm{mol} / \mathrm{L}\right)$. These results indicate that 6 binds more strongly to $A \beta$ aggregates than to ThT $\left(K_{d}=2.3\right.$ $\left.\mu \mathrm{mol} / \mathrm{L}, F_{\mathrm{A} \beta} / F_{0}>111\right)$ and emits a higher fluorescence than BTA-1 $\left(F_{\mathrm{A} \beta} / F_{0}=4.1, K_{\mathrm{d}}=0.30 \mu \mathrm{mol} / \mathrm{L}\right)$. Staining of AD transgenic mouse brains showed that this novel stilbene analog could be a useful imaging tool for AD studies ${ }^{[56]}$.

As early as 2004, Li et al reported two styryl dyes, 2C40 (7)

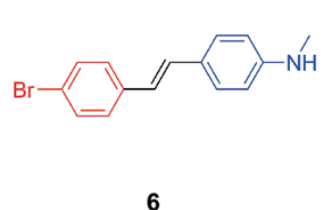

6

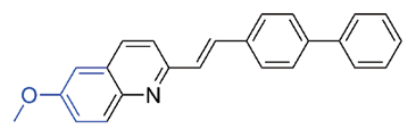

9

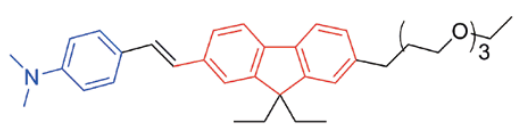

12<smiles></smiles>

$7(2 \mathrm{C} 40)$<smiles>CN(C)c1ccc(/C=C/n2ncc(Cl)c(Cl)c2=O)cc1</smiles>

10

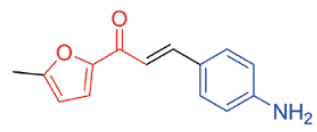

13<smiles>COc1ccc2c(ccc(/C=C/c3ccc(-c4ccccc4)cc3)[n+]2CCN)c1</smiles>

8 (2E10)<smiles>Cc1ccc2nc(/C=C/c3ccc(N)cc3)ccc2c1</smiles>

11

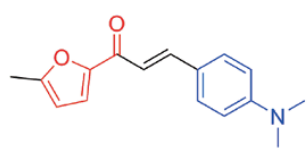

14

Figure 2. Derivatives of stilbene. 
and 2E10 (8), which showed a 27- and 30-fold increase, respectively, in fluorescence after exposure to $A \beta_{1-40}$ fibrils, and a 20 and 16-fold increase, respectively, in fluorescence after exposure to $A \beta_{1-42}$ fibrils. Moreover, these two probes co-stained $\mathrm{A} \beta$ plaques in $\mathrm{AD}$ mouse brain sections ${ }^{[57]}$. In 2007, the same group synthesized novel agents derived from 7 and 8, removing the positive charge and increasing the hydrophobicity for better BBB permeability. One of these compounds, STB-8 (9), showed strong $\mathrm{A} \beta$ plaque staining in $\mathrm{AD}$ brain sections and $\mathrm{a}$ high binding affinity $\left(K_{d}=3.2 \mu \mathrm{mol} / \mathrm{L}\right)$ to $A \beta$ fibrils in solution. In ex vivo experiments, the $A \beta$ plaques stained by 9 were confirmed by ThS co-staining and in vivo staining to overlap with Congo Red in AD transgenic mice. The results of in vivo and ex vivo imaging clearly demonstrated its BBB permeability and specific staining of $\mathrm{A} \beta$ plaques in $\mathrm{AD}$ mice ${ }^{[58]}$.

Park et al discovered compound 9n (10) and found that it exhibited a strong fluorescence response $\left(F_{\mathrm{A} \beta} / F_{0}=40.84\right)$ and binding affinity $\left(K_{d}=1.84 \mu \mathrm{mol} / \mathrm{L}\right)$ to $A \beta$ aggregates. 10 clearly stained both intracellular $A \beta$ aggregates and $A \beta$ plaques in transgenic AD model mice ${ }^{[59]}$. Because the maximal emission wavelength of $\mathbf{1 0}$ when bound to $A \beta$ aggregates is approximately $630 \mathrm{~nm}$ and the molecular weight is suitable for $\mathrm{BBB}$ penetration, 10 would be an excellent NIRF probe for $A \beta$ detection with further in vivo tests.

Staderini et al focused their attention on fluorescent compounds capable of staining $A \beta$ fibrils while simultaneously blocking their aggregation. They developed a compound named 3 (11) that interacted with both $A \beta$ and prion fibrils and stained them with high selectivity. 11 inhibits $A \beta$ selfaggregation in a ThT assay (42.4\% of fluorescence inhibition). Due to its low-toxicity and BBB penetrating ability, $\mathbf{1 1}$ is likely to become the first purposely designed therapeutic and diagnostic tool ${ }^{[60]}$. However, the fluorescence spectrum of $\mathbf{1 1}$ makes it difficult to use in vivo for $\mathrm{A} \beta$ detection.

A recently reported fluorescence probe 1 (12) presented a novel fluorescence-enhancing mechanism. 12 is composed of three important components, an N,N-dimethylamino styrene as the binding unit, a triethylene glycol as the hydrophilic unit and fluorene as an "off-on type" fluorescence signaling unit. When bound to $A \beta$ oligomers and insoluble aggregates, 12 showed disaggregation-induced fluorescence enhancement ${ }^{[61]}$. Although 12 operates under a different mechanism than the other probes, the switch from aggregation to disaggregation depends on the polarity change in the surrounding environment. Therefore, the mechanism of action for $\mathbf{1 2}$ still belongs to the solvent-dependent mode.

Two derivatives of chalcone, probe 5 (13) and probe 6 (14), exhibited a significant increase in fluorescence intensity when bound to $A \beta$ aggregates. The $K_{d}$ values of $\mathbf{1 3}$ and $\mathbf{1 4}$ were 1.59 and $2.30 \mu \mathrm{mol} / \mathrm{L}$, respectively, which indicated a moderate affinity for $\mathrm{A} \beta$ aggregates. These probes specifically stained A $\beta$ plaques in APP/PS1 transgenic mouse brain sections, which was confirmed by co-staining with an A $\beta$ antibody. 13 exhibited a good performance in vitro and was selected for $e x$ vivo experimentation. $\mathbf{1 3}$ was confirmed to penetrate the BBB and to clearly stain A $\beta$ plaques in 14-month-old APP/PS1 mice when compared with normal controls. However, the emission wavelength of $\mathbf{1 3}$ after binding to $A \beta$ aggregates is $532 \mathrm{~nm}$, thus it is still not qualified for in vivo experimentation ${ }^{[62]}$.

\section{Curcumin and its derivatives}

Curcumin (Figure 3, 15), a diarylheptanoid, is the principal curcuminoid of the popular South Asian spice turmeric. In $\mathrm{AD}$ research, $\mathbf{1 5}$ has been shown to have the following properties: anti-A $\beta$ aggregation, anti-oxidation, inhibition of $\beta$-secretase and acetylcholinesterase, and $A \beta$-induced inflammation in vitro ${ }^{[63]}$. Due to its fluorescent properties, 15 labels amyloid plaques, such as ThS in $\mathrm{AD}$ and transgenic mice brain sections, and crosses the $\mathrm{BBB}$ to bind to plaques in vivo ${ }^{[64]}$. In 2007, Garcia-Alloza et al ${ }^{[65]}$ demonstrated that 15 could be applied in detecting $A \beta$ plaques in vivo. However, it was only after 7 days of administration of $\mathbf{1 5}$ that $A \beta$ plaques started to be labeled by 15, reflecting the low efficiency of 15 for in vivo imaging. Moreover, due to its short emission wavelength, practical applications of $\mathbf{1 5}$ as an NIRF probe are limited.

Using a two-step red-shift strategy, Ran et al designed an

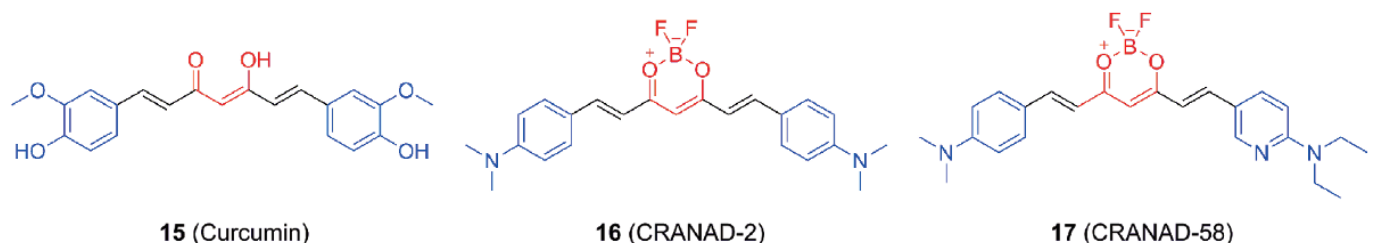

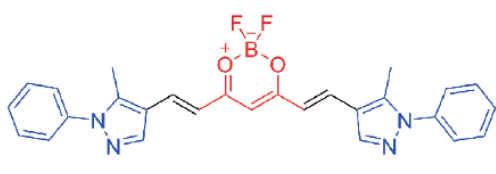

18 (CRANAD-28)

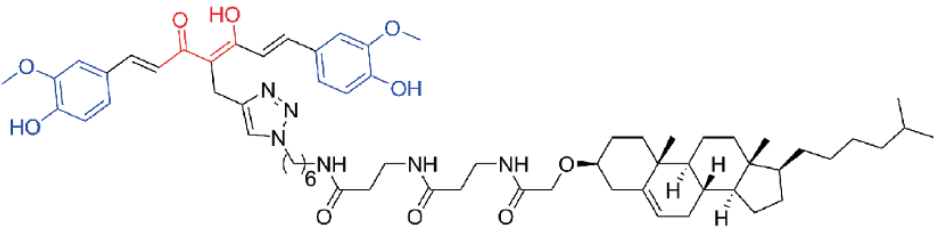

19 (BMAOI 14)

Figure 3. Curcumin and its derivatives. 
NIRF probe derived from curcumin, CRANAD-2 (16). 16 functions as a "smart" probe because of the 70-fold fluorescence intensity increase, an emission blue-shift (from 805 to $715 \mathrm{~nm}$ ), a lifetime change, and quantum yield improvement upon binding to $\mathrm{A} \beta$ aggregates. This probe has a high affinity for $A \beta$ aggregates $\left(K_{d}=38.0 \mathrm{nmol} / \mathrm{L}\right)$, a reasonable $\log P$ value (3), considerable stability in serum, and a weak albumin interaction. Meanwhile, high-contrast plaque staining in transgenic mouse tissue was observed, which colocalized with the signal from standard ThT-stained sections. Moreover, in vivo NIRF imaging indicated that $\mathbf{1 6}$ clearly differentiates between 19-month-old Tg2576 and wild-type mice at early time point $(30 \mathrm{~min})^{[38]}$. One factor limiting in vivo use is the slow washout from the brain.

Although 16 binds to A $\beta$ aggregates/fibrils with high affinity, it lacks the capability to detect soluble $A \beta$ species. To design a probe that is sensitive to soluble $A \beta$ species, Zhang et al studied the structural stereohindrance compatibility of $A \beta$ species and developed a compound called CRANAD-58 (17). 17 showed significant fluorescence property changes upon mixing with both soluble (monomers, dimers, and oligomers) and insoluble A $\beta$ species in vitro. Histological staining of transgenic mice indicated that 17 could specifically highlight $A \beta$ plaques that co-stained with ThS. In vivo NIRF imaging revealed that 17 was capable of differentiating transgenic and wild-type mice as young as 4 months old, an age that lacks visible $A \beta$ plaques as $A \beta$ is likely in its soluble forms ${ }^{[66]}$. The capability to detect soluble $A \beta$ species makes $\mathbf{1 7}$ a promising probe for early $A D$ diagnosis. Nevertheless, due to the neuroprotectivity of $A \beta$ monomers $^{[67]}$, the higher affinity of $\mathbf{1 7}$ for $A \beta$ monomers than other species might limit precise imaging when clinically applied.

Because curcumin is an effective inhibitor of $A \beta$ aggregation, developing derivatives with both diagnostic and therapeutic functions seems possible. A communication published in 2014 reported a high quantum-yielding bifunctional curcumin analog, CRANAD-28 (18). 18 could penetrate the BBB to label plaques and cerebral amyloid angiopathies in a 9-month-old APP/PS1 mouse. Additionally, this probe inhibited copperand naturally (phosphate buffered saline, PBS) induced A $\beta$ crosslinking. Unexpectedly, the fluorescence intensity of $\mathbf{1 8}$ decreased upon mixing with the tested $A \beta$ species, which differs from most other reported probes ${ }^{[68]}$. Further investigation is necessary before this probe could be a theranostic agent for AD.

Another group reported a bivalent ligand, BMAOI 14 (19), which is composed of curcumin and cholesterol. Experimentation demonstrated that 19 bound to $A \beta$ monomers, oligomers, and fibrils with low, micromolar to submicromolar, binding affinities. Furthermore, 19 specifically bound to $A \beta$ plaques in both $\mathrm{AD}$ human patients and $\mathrm{A} \beta$ precursor proteins from transgenic mouse brain tissues. Interestingly, although 19 has a molecular weight of more than $1000 \mathrm{Da}$, it could in fact rapidly cross the $\mathrm{BBB}$, reach the brain tissue and become metabolized in a reasonable time window $(\sim 3 \mathrm{~h})$, suggesting amenability in clinical applications ${ }^{[69]}$. This result suggests that cholesterol could be used as a promoting unit when a probe lacks BBB permeability.

\section{Derivatives of the thiophenes}

NIAD-4 (Figure 4A, 20) was designed with a classical push-pull structure, terminal donor (p-hydroxyphenyl group) moiety, acceptor (dicyanomethylene group) moiety and interconnected by a highly polarizable dithienylethenyl $\Pi$-conjugated bridge. 20 strongly bound to $\mathrm{A} \beta$ fibrils $\left(K_{\mathrm{i}}=10 \mathrm{nmol} / \mathrm{L}\right)$ accompanied by an approximately 400 -fold fluorescence enhancement.

A<smiles>CC(C#N)=Cc1ccc(-c2ccc(-c3ccc(N(C)C)cc3)s2)s1</smiles>

$20($ NIAD-4)

21 (NIAD-11)

22 (NIAD-16)

B<smiles>Cc1nc(O)c(/C=C/C=C/C=C2\C(=O)N=C(S)N=C2O)c(O)n1</smiles>

23 (THK-265)<smiles>COC(=O)/C(C#N)=C/C=C/C=C/c1ccc(N(C)C)cc1</smiles>

25 (MCAAD-3)<smiles>CN(C)c1ccc(/C=C/C=C/C=C(C#N)C#N)cc1</smiles>

24 (DANIR-2c)<smiles>CN(C)c1ccc2cc3c(cc2c1)OCC(C=C(C#N)C#N)=C3</smiles>

26

Figure 4. Derivatives of thiophenes (A) and alkatrienes (B). 
Additionally, it readily crossed the BBB after an intravenous injection and specifically labeled both the plaques and cerebrovascular amyloid angiopathies in living brain tissue ${ }^{[37]}$.

The maximal emission wavelength of 20 is $612 \mathrm{~nm}$, outside the NIR range $(650-950 \mathrm{~nm})$. Based on the structure of 20, NIAD-11 $\left(\lambda_{\max }=690 \mathrm{~nm}\right)(21)$ and NIAD-16 $\left(\lambda_{\max }=720 \mathrm{~nm}\right)(22)$ were then synthesized. 21 exhibited a significant fluorescent increase and a $15-\mathrm{nm}$ red-shift in the emission wavelength when bound to $A \beta$ aggregates. 22 clearly stained $A \beta$ plaques in $\mathrm{AD}$ mouse brain sections ${ }^{[70]}$.

\section{Derivatives of the alkatrienes}

THK-265 (Figure 4B, 23) is an NIRF probe with an alkatriene chain bridging two pyrimidine rings. It has a maximal emission wavelength of more than $650 \mathrm{~nm}$, a high quantum yield (38.5\% in methanol solution), a high affinity $\left(K_{d}=97 \mathrm{nmol} / \mathrm{L}\right)$ for $\mathrm{A} \beta$ fibrils and a moderate $\log P$ value (1.8). Ex vivo fluorescence imaging of brain samples in mice indicated a fast washout ( $>60 \%$ reduction of fluorescence within $60 \mathrm{~min}$ ) of $\mathbf{2 3}$ from the brain. In vivo NIRF imaging demonstrated significantly higher fluorescence intensity in the brains of AD transgenic mice than in those of wild-type mice, even as early as 3 min in both 19- and 32-month-old APP/PS1 transgenic mice ${ }^{[71]}$. These results suggest that $\mathbf{2 3}$ could be a potential NIRF imaging probe for $\mathrm{AD}$ diagnosis.

Recently, Cui et al reported an NIRF probe, DANIR-2c (24), with a traditional donor-acceptor structure bridged by an alkatriene chain. 24 demonstrated a high affinity for $A \beta$ aggregates in vitro $\left(K_{\mathrm{d}}=26.9 \mathrm{nmol} / \mathrm{L}, K_{\mathrm{i}}=36.9 \mathrm{nmol} / \mathrm{L}\right)$ and stained $\mathrm{A} \beta$ plaques in brain sections from an $\mathrm{AD}$ patient and transgenic mice. It has a maximal emission wavelength of $665 \mathrm{~nm}$, high in vitro stability in mouse serum, low cytotoxicity to human neuronal cells and ideal brain kinetics in normal nude mice. Additionally, in vivo NIRF imaging indicated a significant contrast in the fluorescent signal in brain regions of 22-month-old wild-type and APP/PS1 transgenic mice at 30 min post-injection of $\mathbf{2 4}^{[72]}$. With a molecular weight of $249 \mathrm{Da}$, 24 may have the simplest structure of all of the $A \beta$ NIRF probes. However, the blue-shift of $\mathbf{2 4}$ upon binding to $A \beta$ means that further red-shifting of the maximal emission wavelength is required to make it a promising $\mathrm{A} \beta \mathrm{NIRF}$ probe for $\mathrm{AD}$ diagnosis.

Fu et al introduced new acceptor moieties to the backbone of $\mathbf{2 4}$ and synthesized four novel NIRF probes with emission wavelengths ranging from 685 to $725 \mathrm{~nm}$, longer than the 665 $\mathrm{nm}$ of 24. Among them, MCAAD-3 (25) displayed the highest fluorescence increase (26-fold) and affinity $\left(K_{d}=106.0 \mathrm{nmol} / \mathrm{L}\right)$ when bound to $A \beta$ aggregates. 25 readily penetrated the $B B B$, and as a result was selected for in vivo imaging in mice. The differences in the fluorescence signals between the transgenic and the wild-type mice could be seen after $30 \mathrm{~min}$ of injection. The in vivo results were confirmed by an ex vivo staining experiment. The authors conducted additional molecular docking simulations to explore the possible binding sites of their probes, which could provide insight into the discovery of novel $\mathrm{A} \beta$ probes $^{[73]}$.

To address the critical issue of autofluorescence in imaging,
Kim et al synthesized a novel class of two-photon absorbing dyes that are classified as $\Pi$-extended acedan analogs. Because limited autofluorescence is advantageous in tissue imaging and in vivo imaging of $A \beta$ plaques, the authors synthesized compound 5 (26), an analog of 24.26 exhibited a 41 - to 61 -fold increase in fluorescence upon binding to $A \beta$ aggregates, with little interference from bovine serum albumin (BSA). It showed a high affinity for $A \beta$ aggregates with a $K_{d}$ of 44.6 $\mathrm{nmol} / \mathrm{L}$. In vivo imaging provided clear, bright red fluorescence images of $A \beta$ plaques with little autofluorescence. It is believed that with proper instruments, two-photon probes would allow deeper tissue imaging in animals ${ }^{[74]}$.

\section{BODIPY-derived probes}

Boron-dipyrromethene, BODIPY, is a classical fluorescent dye applied in a variety of fields ${ }^{[75]}$. Many notable features of BODIPY, such as the robustness against light and chemicals, the relatively high molar absorption coefficients and fluorescence quantum yields, the sharp emission bandwidths with high peak intensities, good solubility, excitation/emission wavelengths in the visible spectral region $(\geq 500 \mathrm{~nm})$, and fluorescence lifetimes in the nanosecond range, all contribute to the appeal of this structure as an important tool in a variety of imaging applications, as Boens et al reviewed ${ }^{[76]}$.

Parhi et al reported the first exploration of synthesizing BODIPY-based fluorescent probes for detecting $A \beta$ plaques ${ }^{[7]}$. However, they only characterized these probes chemically (the probes do not have off-on property) and no biological results were reported. Smith et al reported triazole-containing BODIPY dyes that showed different fluorescence increases in the presence of soluble $A \beta_{1-42}$ oligomers with both unordered and ordered $\beta$-sheet-rich conformations ${ }^{[78]}$. Nonetheless, no further application of these dyes as $A \beta$ fluorescent imaging probes has been reported.

A BODIPY-derived probe, BODIPY-7 (Figure 5, 27), was designed as a dual SPECT/fluorescent probe for imaging $A \beta$ plaques in the brain. The radiolabeled 27 , does not have characteristics for imaging $A \beta$ plaques. Although 27 had a high fluorescent quantum yield $(\Phi=0.36)$, it exhibited shorter wavelengths of absorption/emission, at $606 / 613 \mathrm{~nm}$, than those appropriate for optical imaging in vivo ${ }^{[79]}$. Another BODIPYderived probe, BAP-1 (28), with a maximal emission wavelength of $648 \mathrm{~nm}$, showed excellent efficacy both in vitro and in vivo. 28 bound to $A \beta$ aggregates with a high affinity $\left(K_{\mathrm{d}}=44.1 \mathrm{nmol} / \mathrm{L}\right)$ and clearly stained $\mathrm{A} \beta$ plaques in the brains of transgenic mice. Moreover, 28 possesses ideal metabolic kinetics in vivo and could clearly differentiate between 25-month-old wild-type and Tg2576 mice at $1 \mathrm{~h}$ post-injection ex vivo ${ }^{[80]}$. The same group also developed derivatives of 28, BAP-2 (29), BAP-3 (30), BAP-4 (31), and BAP-5 (32), which contain most of the advantageous features of 28 but a better maximal emission wavelength, up to $700 \mathrm{~nm}$. The estimated $K_{d}$ values for 29, 30, 31, and 32 were 55, 149, 27, and 18 $\mathrm{nmol} / \mathrm{L}$, respectively, suggesting a high affinity for $A \beta_{1-42}$ aggregates. These probes could clearly stain plaques in Tg2576 mice brain sections. One of these probes, 29, exhibited 


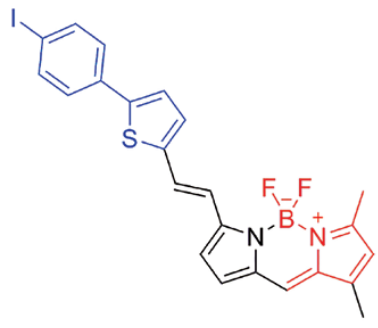

27 (BODIPY-7)

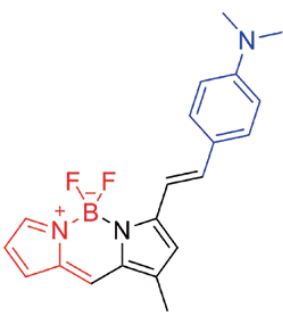

28 (BAP-1)

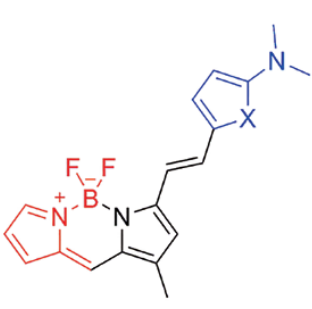

$29(\mathrm{X}=\mathrm{S}: \mathrm{BAP}-2)$ $30(\mathrm{X}=\mathrm{O}: \mathrm{BAP}-3)$

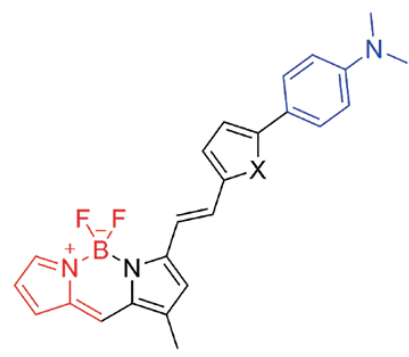

31 (X=S: BAP-4) $32(\mathrm{X}=\mathrm{O}: \mathrm{BAP}-5)$

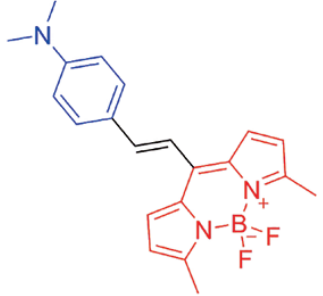

33 (EUA-1)

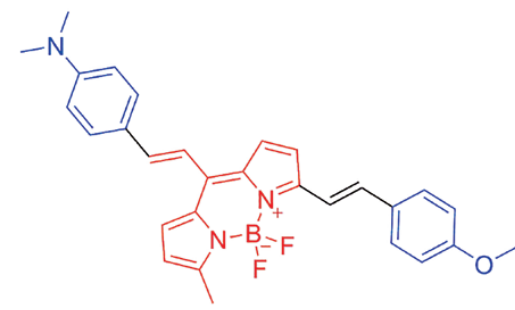

34 (EUA-2)

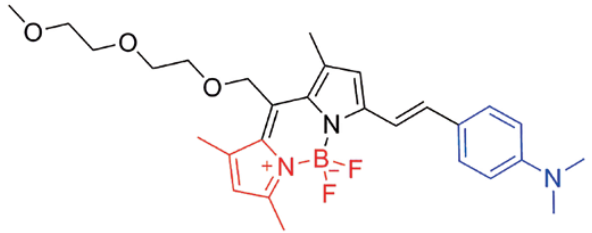

35 (EUA-4)

Figure 5. Derivatives of BODIPYs.

ideal brain kinetics and was chosen for ex vivo experimentation, in which 29 showed selective binding of $A \beta$ plaques with little nonspecific binding. However, 29 could not differentiate between transgenic and wild-type mice in vivo and showed higher accumulation in the scalp than in the brain in both groups ${ }^{[81]}$. This result suggests that appropriate structural modifications to BODIPY derivatives are necessary for future in vivo applications.

Sozmen et al designed and synthesized a series of styryl-conjugated BODIPY dyes (EUA1-5) for fluorescence imaging of $\mathrm{A} \beta$ plaques. The emission wavelengths of these probes ranged from 654 to $763 \mathrm{~nm}$. The dissociation constants of EUA1-5 were 320, 230, 320, 48.6 and $97 \mathrm{nmol} / \mathrm{L}$, respectively. Among these probes, EUA-1 (33), EUA-2 (34) and EUA-4 (35) stained the Tg2576 mice brain sections efficiently and demonstrated good patterning ${ }^{[82]}$. With the highest affinity and best fluorescence staining, 35 would be a promising diagnostic agent after further modification.

\section{Other probes}

In 2005, Novartis developed an oxazine-derivative NIRF probe, AOI-987 (Figure 6, 36), which could penetrate BBB and bind to $A \beta$ plaques ${ }^{[83]}$. However, the signal contrast between the wild-type and transgenic mice was not significant, probably due to the low fluorescence enhancement upon binding to $A \beta$ aggregates observed in vitro. Structurally, $\mathbf{3 6}$ is categorized as a donor-acceptor but with a rigidified bridge, which may explain the non-optimal properties of 36 .

Based on the donor-acceptor structure, Chang et al designed and synthesized a new family of fluorescent markers containing an amino naphthalenyl-2-cyano-acrylate (ANCA) motif. One of these compounds, ANCA-11 (37), showed increased fluorescence upon binding to $A \beta$ aggregates (7.7-fold) and the highest binding affinity $\left(K_{\mathrm{d}}=1.4 \mu \mathrm{mol} / \mathrm{L}\right)$ among all compounds. In vitro tests indicated that all of the compounds could fluorescently stain amyloid deposits in human brain tissue from AD patients ${ }^{[35]}$. However, further improvement of the binding affinity and maximal emission wavelengths of these probes is needed.

Gemma et al reported the identification and preliminary characterization of a new class of pyrrolo (imidazo) quinoxaline hydrazones (38) as fluorescent probes for $A \beta$ fibrils. Except for the relatively high basic fluorescence intensities of the analyzed probes, the level of fluorescence changes when<smiles>CN1CCOc2cc3c(cc21)Oc1cc2c(cc1=C3)OCC[N+]=2C</smiles>

36 (AOI-987)<smiles>COCCOCCOCCOC(=O)/C(C#N)=C/c1ccc2cc(N3CCCCC3)ccc2c1</smiles>

37 (ANCA-11)<smiles>C(=N/Nc1nc2ccccc2n2cccc12)\c1ccnc2ccccc12</smiles>

38

Figure 6. Other probes. 
mixed with $\mathrm{A} \beta$ fibrils is similar to that of ThT. Histological staining of AD mice suggested that these probes specifically recognize the $\beta$-pleated sheet structure of $A \beta$ fibrils equivalently to the standard dyes such as ThS or Congo Red ${ }^{[84]}$. The advantage of these probes over traditional ThS or Congo Red is their BBB penetrating ability.

\section{The solvent-independent mode as a new mode of $A \beta$ labeling}

Fluorescence self-quenching is not a new concept. In 1990, Munkholm et al reported that fluoresceinamine, which has markedly quenched fluorescence, could be turned on by the conversion of its amine to an amide ${ }^{[85]}$. Therefore, fluoresceinamine could be used as a highly sensitive $\mathrm{pH}$ indicator. This compound has the very attractive feature of reducing background fluorescence when performing in vivo imaging, potentially allowing real-time imaging without a washing or clearance step ${ }^{[86]}$. In regard to biomolecule sensing (insulin, $A \beta$ aggregates, etc), the above-mentioned mechanism lacks scope for its abilities. Kim et $a l^{[87]}$ systematically studied the fluorescent off-on mechanism for probes in which the fluorophore and the quencher are connected by a spacer. Changes in the distance between the fluorophore and the quencher, induced by solvent alteration, underlie the off-on mechanism.

Due to the high quantum yield, resistance to solvent polarity and $\mathrm{pH}$, BODIPY-based fluorophores with off-on mechanisms for small-molecule sensing have already been developed ${ }^{[86,88,89]}$. However, no such probes have been developed for detecting macromolecules, such as $A \beta$ aggregates.

Based on the off-on mechanism and features of BODIPYs, we synthesized different scaffolds and discovered molecule probe 1 (Figure 7, 39), which has an aniline group as the quencher and a nonpolar BODIPY as the fluorophore. 39 showed a high affinity for $A \beta$ aggregates with a $K_{d}$ of $3.5 \mathrm{nmol} / \mathrm{L}$. It clearly stained brain sections of APP/PS1 transgenic mice without a washing process. The plaques stained by $\mathbf{3 9}$ were co-stained by an $A \beta$ specific antibody, further verifying its ability to label $\mathrm{A} \beta$ plaques with an off-on mechanism. Unlike other reported probes, this probe has almost no fluorescence in both polar and nonpolar solvents. After binding to A $\beta$ aggregates, 39 exhibited a significant increase in fluorescence. We propose that the distance between the quenching group and BODIPY core would increase when the BODIPY motif bound to $A \beta$ fibrils, and then the fluorescence of the probe would turn on ${ }^{[90]}$.

The decreased environmental sensitivity and lack of washing procedure during high contrast brain tissue staining are

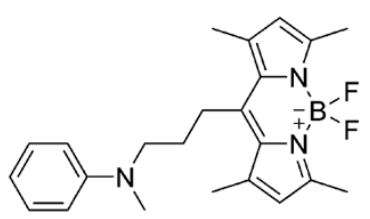

39

Figure 7. Structure of probe 39. advantages to 39 that make probes with this type of mode applicable to future in vivo imaging. We are now focusing on bathochromic shifting the emission wavelength of 39 to the NIR region on the premise of retaining its high $\mathrm{A} \beta$ binding activity.

\section{Conclusions and future prospectives}

Over the past decade, a variety of fluorescent probes have been developed for labeling $A \beta$ in vitro and in vivo. Most of these probes adopt a solvent-dependent mode with traditional donor-acceptor structures. Upon binding to the $A \beta$ species, these probes exhibit enhanced fluorescence emission, a phenomenon often described as fluorescence "turn on". Theoretically, this property allows these probes to be used as contrast agents for $A \beta$ detection in vitro and in vivo, especially when compared to those fluorophores with $\mathrm{A} \beta$ binding affinity but no fluorescence change.

In reality, a large number of the reported probes showed efficacy in vitro but lack in vivo results. One of the probable reasons is a maximal emission below the NIR range (650-900 $\mathrm{nm})$. NIRF probes are suited for in vivo detection due to their higher tissue penetration and lower background when compared to non-NIR probes. However, reported probes are often derived from already existent dyes with maximal emission wavelengths less than $600 \mathrm{~nm}$. Only after further red-shifting of the probes is there potential for use in animals, presuming unaltered fluorescence properties.

Another probable reason for the lack of in vivo data is low BBB permeability. Traditional dyes, such as ThT and Congo Red, lack BBB penetration due to their charge or large molecular weight. Their improved derivatives are often neutral or have small molecular weights, which are suitable properties for the non-polarity needed to cross the BBB. However, the larger the non-polarity the lower the labeling specificity. Therefore, a balance between BBB penetration and labeling specificity should be maintained, which is a limiting factor in vivo. Of all of the currently available $A \beta$ NIRF probes that have been administered in vivo, only probes 17, 24 and 25 showed fast BBB permeability. After further modifications, these probes hold promise for early AD diagnosis.

Although much progress has been made during the last decade, there is still a long way to go before $A \beta$ fluorescent probes truly have a foothold in the field of AD diagnosis. There is much room for improvement with the existing probes. (1) NIRF probes only account for a small number of probes, so red-shifting the existing probes is a current focus. (2) Most probes can only detect insoluble $A \beta$ fibrils or plaques, and probes capable of targeting the soluble species, such as oligomers, are scarce. (3) A large number of recently discovered probes originate from traditional scaffolds with unsuitable properties for in vivo testing, so finding new scaffolds is an important task. (4) Although the traditional solventdependent mode is the leading mechanism of testing current probes (Table 1), introducing new mechanisms would help in discovering more efficient probes for in vivo imaging.

This review introduced for the first time an emerging mode 
Table 1. Characteristics of representative probes with solvent-dependent mode.

\begin{tabular}{|c|c|c|c|c|c|c|}
\hline Probes & $\lambda_{\mathrm{ex}} / \lambda_{\mathrm{em}}(\mathrm{nm})^{\mathrm{a}}$ & Finished stage & $\mathrm{A} \beta$ species detected & $K_{d} / K_{i} / I_{50}$ & Fold increase & Ref \\
\hline \multicolumn{7}{|c|}{ ThT \& its derivatives } \\
\hline 1 & $450 / 482$ & in vitro & $A \beta_{40}$ fibrils & $K_{\mathrm{i}}=890 \mathrm{nmol} / \mathrm{L}$ & - & [91] \\
\hline 2 & - & in vitro & $A \beta$ fibrils & $K_{\mathrm{i}}=4.38 \mathrm{nmol} / \mathrm{L}$ & - & [52] \\
\hline 3 & $340 / 410$ & in vitro & $A \beta_{40}$ fibrils & $K_{d}=3.27 \mu \mathrm{mol} / \mathrm{L}$ & 36.1 & [53] \\
\hline 4 & $540 / 634$ & in vitro & $A \beta_{42}$ fibrils & $\mathrm{IC}_{50}=0.12 \mu \mathrm{mol} / \mathrm{L}$ & - & [54] \\
\hline 6 & $350 / 440$ & in vitro & $A \beta_{40}$ fibrils & $K_{\mathrm{d}}=1.13 \mu \mathrm{mol} / \mathrm{L}$ & 25 & [56] \\
\hline \multirow[t]{2}{*}{7} & \multirow[t]{2}{*}{$505 / 590$} & \multirow[t]{2}{*}{ in vitro } & $A \beta_{40}$ fibrils & - & 27 & \multirow[t]{2}{*}{ [57] } \\
\hline & & & $A \beta_{42}$ fibrils & - & 20 & \\
\hline \multirow[t]{2}{*}{8} & $464 / 503$ & in vitro & $A \beta_{40}$ fibrils & - & 30 & [57] \\
\hline & & & $A \beta_{42}$ fibrils & - & 16 & \\
\hline 9 & $373 / 407$ & in vitro & $A \beta_{40}$ fibrils & $K_{d}=3.20 \mu \mathrm{mol} / \mathrm{L}$ & - & [58] \\
\hline 13 & $400 / 570$ & in vitro/ex vivo & $A \beta_{42}$ fibrils & $K_{\mathrm{d}}=1.59 \mu \mathrm{mol} / \mathrm{L}$ & 49.9 & [62] \\
\hline 14 & $438 / 582$ & in vitro & $A \beta_{42}$ fibrils & $K_{d}=2.30 \mu \mathrm{mol} / \mathrm{L}$ & 58.9 & [62] \\
\hline Derivati & $\min$ & & & & & \\
\hline 16 & $640 / 715$ & in vivo & $A \beta_{40}$ fibrils & $K_{\mathrm{d}}=38.0 \mathrm{nmol} / \mathrm{L}$ & 70 & [38] \\
\hline 17 & $630 / 672$ & in vivo & $A \beta_{40}$ monomers & $K_{d}=105.8 \mathrm{nmol} / \mathrm{L}$ & 91.9 & [66] \\
\hline & & & $\mathrm{A} \beta_{42}$ monomers & $K_{d}=45.8 \mathrm{nmol} / \mathrm{L}$ & 113.6 & \\
\hline & & & $A \beta_{40}$ dimers & - & 60 & \\
\hline & & & $A \beta_{40}$ fibrils & - & - & \\
\hline & & & $A \beta_{42}$ oligomers & - & - & \\
\hline 18 & $498 / 578$ & in vivo & $\mathrm{A} \beta_{40}$ monomers & $K_{\mathrm{d}}=68.8 \mathrm{nmol} / \mathrm{L}$ & - & [68] \\
\hline & & & $A \beta_{42}$ monomers & $K_{d}=159.7 \mathrm{nmol} / \mathrm{L}$ & - & \\
\hline 21 & $545 / 690$ & in vivo & $A \beta_{40}$ fibrils & - & - & [70] \\
\hline 22 & $470 / 720$ & in vivo & $A \beta_{40}$ fibrils & - & - & [70] \\
\hline Derivati & ienes & & & & & \\
\hline 23 & $650 / 680$ & in vivo & $A \beta$ fibrils & $K_{d}=97 \mathrm{nmol} / \mathrm{L}$ & - & [71] \\
\hline 24 & $597 / 625$ & in vivo & $A \beta_{42}$ fibrils & $\begin{array}{l}K_{\mathrm{d}}=26.9 \mathrm{nmol} / \mathrm{L} \\
K_{\mathrm{i}}=36.9 \mathrm{nmol} / \mathrm{L}\end{array}$ & 12 & [72] \\
\hline 25 & $596 / 685$ & in vivo & $A \beta_{42}$ fibrils & $K_{d}=106.0 \mathrm{nmol} / \mathrm{L}$ & 26 & [73] \\
\hline 26 & $500 / 670$ & in vivo & $A \beta_{42}$ fibrils & $K_{d}=44.6 \mathrm{nmol} / \mathrm{L}$ & 60 & [74] \\
\hline BODIPY & bes & & & & & \\
\hline 27 & $606 / 613$ & in vitro & $A \beta_{42}$ fibrils & $K_{\mathrm{i}}=108 \mathrm{nmol} / \mathrm{L}$ & - & [79] \\
\hline 28 & $614 / 648$ & in vitro/ex vivo & $A \beta_{42}$ fibrils & $K_{\mathrm{d}}=44.1 \mathrm{nmol} / \mathrm{L}$ & - & [80] \\
\hline 29 & $650 / 708$ & in vitro/ex vivo & $A \beta_{42}$ fibrils & $K_{d}=55 \mathrm{nmol} / \mathrm{L}$ & - & [81] \\
\hline 30 & $663 / 705$ & in vitro & $A \beta_{42}$ fibrils & $K_{\mathrm{d}}=149 \mathrm{nmol} / \mathrm{L}$ & - & [81] \\
\hline 31 & $636 / 704$ & in vitro & $A \beta_{42}$ fibrils & $K_{d}=27 \mathrm{nmol} / \mathrm{L}$ & - & [81] \\
\hline 32 & $649 / 723$ & in vitro & $A \beta_{42}$ fibrils & $K_{d}=18 \mathrm{nmol} / \mathrm{L}$ & - & [81] \\
\hline 33 & $518 / 654$ & in vitro & $A \beta_{42}$ fibrils & $K_{d}=322.8 \mathrm{nmol} / \mathrm{L}$ & - & [82] \\
\hline 34 & $597 / 667$ & in vitro & $A \beta_{42}$ fibrils & $K_{d}=226.2 \mathrm{nmol} / \mathrm{L}$ & - & [82] \\
\hline 35 & $624 / 673$ & in vitro & $A \beta_{42}$ fibrils & $K_{d}=48.6 \mathrm{nmol} / \mathrm{L}$ & - & [82] \\
\hline Other $p$ & & & & & & \\
\hline 36 & $650 / 705$ & in vivo & $A \beta_{40}$ fibrils & $K_{\mathrm{d}}=0.22 \mu \mathrm{mol} / \mathrm{L}$ & - & [83] \\
\hline 37 & $415 / 590$ & in vitro & $A \beta_{42}$ fibrils & $K_{\mathrm{d}}=1.40 \mu \mathrm{mol} / \mathrm{L}$ & 7.7 & [35] \\
\hline 38 & $390 / 481$ & in vitro & $A \beta_{42}$ fibrils & - & - & [84] \\
\hline
\end{tabular}

${ }^{a}$ Wavelengths measured without binding to $A \beta$ fibrils/aggregates. 
for developing $\mathrm{A} \beta$ fluorescent probes, the solvent-independent mode that has a different mechanism of fluorescence enhancement than other existing probes. Our results from staining the brains of APP/PS1 mice suggested that traditional probes, such as ThS, and recent NIRF probes, such as $\mathbf{1 7}$, could not differentiate between wild-type and transgenic mice without a washing process. A probable explanation for this phenomenon is the interaction between residual probes and a nonpolar environment, overwhelming the $A \beta$ signals. By contrast, our probe 39 clearly stained $A \beta$ plaques even without a washing process. The further consolidated off-on mode of $\mathbf{3 9}$ holds possibility for future in vivo imaging as the high signal-tobackground ratio can compensate for the low spatial resolution of NIRF imaging.

Identifying new biomarkers for early $\mathrm{AD}$ diagnosis meet difficult challenges. As we mentioned, $A \beta$ oligomers, which have attracted increasing attention in understanding $A \beta$ toxicity mechanisms, show great potential in early AD diagnosis. $A \beta$ accumulation is known to start one to two decades before evident syndromes occur, and aggregated $A \beta$ oligomers are believed to form early in this process. Therefore, examining the role of $A \beta$ oligomers as a predictive marker requires a long period of longitudinal research. The results from probe 17 suggest that at 4-months, when $A \beta$ is believed to be in an oligomeric form, a significant signal was detected in transgenic mice, suggesting that $A \beta$ oligomers could be used as a potential marker for early diagnosis. Nevertheless, there are few probes capable of detecting $A \beta$ oligomers, and fewer are NIRF probes that have been examined in vivo.

Currently, NIRF imaging technology has been widely used in different disease animal models and a non-specific contrast agent, ICG, has been used in off-label human clinical studies ${ }^{[92,93]}$. However, the NIRF imaging devices and probes are the two main limiting factors for future clinical application of disease-specific imaging, as Sevick-Muraca reviewed ${ }^{[94]}$. Of course, better NIRF imaging systems and probes with high signal-to-background ratios are expected to improve the specificity, sensitivity and spatial resolution to match the efficacy of PET. With a high efficacy and low cost, AD NIRF imaging could become a widely accepted future diagnostic method.

\section{Acknowledgements}

This work was supported by the National Natural Science Foundation of China (№ 81522045 and 81225022).

\section{References}

1 Panza F, Solfrizzi V, Imbimbo BP, Tortelli R, Santamato A, Logroscino G. Amyloid-based immunotherapy for Alzheimer's disease in the time of prevention trials: the way forward. Expert Rev Clin Immunol 2014; 10 : 405-19.

2 Selkoe DJ. Alzheimer's disease: genes, proteins, and therapy. Physiol Rev 2001; 81: 741-66.

3 World Alzheimer report 2013 (http://www.alz.co.uk/sites/default/ files/pdfs/WorldAlzheimerReport2013.pdf)

4 Dubois B, Feldman HH, Jacova C, Dekosky ST, Barberger-Gateau P, Cummings $\mathrm{J}$, et al. Research criteria for the diagnosis of Alzheimer's disease: revising the NINCDS-ADRDA criteria. Lancet Neurol 2007; 6:
734-46.

5 Schmechel DE, Saunders AM, Strittmatter WJ, Crain BJ, Hulette CM, Joo SH, et al. Increased amyloid beta-peptide deposition in cerebral cortex as a consequence of apolipoprotein E genotype in late-onset Alzheimer disease. Proc Natl Acad Sci U S A 1993; 90: 9649-53.

6 Armstrong RA, Cairns NJ, Myers D, Smith CU, Lantos PL, Rossor MN. A comparison of $\beta$-amyloid deposition in the medial temporal lobe in sporadic Alzheimer's disease, Down's syndrome and normal elderly brains. Neurodegeneration 1996; 5: 35-41.

7 Cataldo AM, Barnett JL, Pieroni C, Nixon A. Increased neuronal endocytosis and protease delivery to early endosomes in sporadic Alzheimer's disease: neuropathologic evidence for a mechanism of increased $\beta$-amyloidogenesis. J Neurosci 1997; 17: 6142-51.

8 Yang LB, Lindholm K, Yan R, Citron M, Xia W, Yang XL, et al. Elevated beta-secretase expression and enzymatic activity detected in sporadic Alzheimer disease. Nat Med 2003; 9: 3-4.

9 Li R, Lindholm K, Yang LB, Yue X, Citron M, Yan R, et al. Amyloid beta peptide load is correlated with increased beta-secretase activity in sporadic Alzheimer's disease patients. Proc Natl Acad Sci U S A 2004; 101: 3632-7.

10 Villemagne VL, Burnham S, Bourgeat P, Brown B, Ellis KA, Salvado O, et al. Amyloid $\beta$ deposition, neurodegeneration, and cognitive decline in sporadic Alzheimer's disease: a prospective cohort study. Lancet Neurol 2013; 12: 357-67.

11 Sisodia SS, Price DL. Role of the beta-amyloid protein in Alzheimer's disease. FASEB J 1995; 9: 366-70.

12 Cummings BJ, Cotman CW. Image analysis of beta-amyloid load in Alzheimer's disease and relation to dementia severity. Lancet 1995; 346: 1524-8.

13 Chételat G, Villemagne VL, Bourgeat P, Pike KE, Jones G, Ames D, et al. Relationship between atrophy and beta-amyloid deposition in Alzheimer disease. Ann Neurol 2010; 67: 317-24.

14 Selkoe DJ. Amyloid $\beta$-protein and the genetics of Alzheimer's disease. J Biol Chem 1996; 271: 18295-8.

15 Steiner H, Capell A, Leimer U, Haass C. Genes and mechanisms involved in beta-amyloid generation and Alzheimer's disease. Eur Arch Psy Clin N 1999; 249: 266-70.

16 Murphy MP, LeVine H 3rd. Alzheimer's disease and the amyloid-beta peptide. J Alzheimers Dis 2010; 19: 311-23.

17 Jonsson T, Atwal JK, Steinberg S, Snaedal J, Jonsson PV, Bjornsson $\mathrm{S}$, et al. A mutation in APP protects against Alzheimer's disease and age-related cognitive decline. Nature 2012; 488: 96-9.

18 Goldsworthy MR, Vallence AM. The role of $\beta$-amyloid in Alzheimer's disease-related neurodegeneration. J Neurosci 2013; 33: 12910-1.

19 Wirth M, Villeneuve S, La Joie R, Marks SM, Jagust WJ. Geneenvironment interactions: lifetime cognitive activity, APOE genotype, and $\beta$-amyloid burden. J Neurosci 2014; 34: 8612-7.

20 Brookmeyer R, Gray S, Kawas C. Projections of Alzheimer's disease in the United States and the public health impact of delaying disease onset. Am J Public Health 1998; 88: 1337-42.

21 Alzheimer's Association. 2009 Alzheimer's disease facts and figures. Alzheimers Dement 2009; 5: 234-70.

22 Moonis M, Swearer JM, Dayaw MP, St George-Hyslop P, Rogaeva $\mathrm{E}$, Kawarai T, et al. Familial Alzheimer disease: decreases in CSF Abeta42 levels precede cognitive decline. Neurology 2005; 65: 323-5.

23 Klunk WE, Price JC, Mathis CA, Tsopelas ND, Lopresti BJ, Ziolko $\mathrm{SK}$, et al. Amyloid deposition begins in the striatum of presenilin-1 mutation carriers from two unrelated pedigrees. J Neurosci 2007; 27: 6174-84.

24 Ringman JM, Younkin SG, Pratico D, Seltzer W, Cole GM, Geschwind 
$\mathrm{DH}$, et al. Biochemical markers in persons with preclinical familial Alzheimer disease. Neurology 2008; 71: 85-92.

25 Reiman EM, Chen K, Liu X, Bandy D, Yu M, Lee W, et al. Fibrillar amyloid-beta burden in cognitively normal people at 3 levels of genetic risk for Alzheimer's disease. Proc Natl Acad Sci U S A 2009; 106: 6820-5.

26 Sperling RA, Aisen PS, Beckett LA, Craft S, Fagan AM, Iwatsubo T, et al. Toward defining the preclinical stages of Alzheimer's disease: recommendations from the National Institute on Aging-Alzheimer's Association workgroups on diagnostic guidelines for Alzheimer's disease. Alzheimers Dement 2011; 7: 280-92.

27 Bruggink KA, Jongbloed W, Biemans EA, Veerhuis R, Claassen $\mathrm{JA}$, Kuiperij $\mathrm{HB}$, et al. Amyloid- $\beta$ oligomer detection by ELISA in cerebrospinal fluid and brain tissue. Anal Biochem 2013; 433: 112-20.

28 Cui M. Past and recent progress of molecular imaging probes for $\beta$-amyloid plaques in the brain. Curr Med Chem 2014; 21: 82-112.

29 Amatsubo T, Yanagisawa D, Morikawa S, Taguchi H, Tooyama I. Amyloid imaging using high-field magnetic resonance. Magn Reson Med Sci 2010; 9: 95-9.

30 Camus V, Payoux P, Barré L, Desgranges B, Voisin T, Tauber C, et al. Using PET with 18F-AV-45 (florbetapir) to quantify brain amyloid load in a clinical environment. Eur J Nucl Med Mol Imaging 2012; 39 : 621-31.

31 Rosenberg PB, Wong DF, Edell SL, Ross JS, Joshi AD, Brašić JR, et al. Cognition and amyloid load in Alzheimer disease imaged with florbetapir F 18(AV-45) positron emission tomography. Am J Geriatr Psychiatry 2013; 21: 272-8.

32 Nelissen N, Van Laere K, Thurfjell L, Owenius R, Vandenbulcke $\mathrm{M}$, Koole M, et al. Phase 1 study of the Pittsburgh compound $\mathrm{B}$ derivative $18 \mathrm{~F}$-flutemetamol in healthy volunteers and patients with probable Alzheimer disease. J Nucl Med 2009; 50: 1251-9.

33 Wong DF, Moghekar AR, Rigamonti D, Brašić JR, Rousset O, Willis W, et al. An in vivo evaluation of cerebral cortical amyloid with ((18) F) flutemetamol using positron emission tomography compared with parietal biopsy samples in living normal pressure hydrocephalus patients. Mol Imaging Biol 2013; 15: 230-7.

34 Zhou M, Wang X, Liu Z, Yu L, Hu S, Chen L, et al. Advances of molecular imaging probes for the diagnosis of Alzheimer's disease. Curr Alzheimer Res 2014; 11: 221-31.

35 Chang WM, Dakanali M, Capule CC, Sigurdson CJ, Yang J, Theodorakis EA. ANCA: A family of fluorescent probes that bind and stain amyloid plaques in human tissue. ACS Chem Neurosci 2011; 2: 249-55.

36 Weissleder R, Ntziachristos V. Shedding light onto live molecular targets. Nat Med 2003; 9: 123-8.

37 Nesterov EE, Skoch J, Hyman BT, Klunk WE, Bacskai BJ, Swager TM. In vivo optical imaging of amyloid aggregates in brain: design of fluorescent markers. Angew Chem Int Ed Engl 2005; 44: 5452-6.

38 Ran C, Xu X, Raymond SB, Ferrara BJ, Neal K, Bacskai BJ, et al. Design, synthesis, and testing of difluoroboron-derivatized curcumins as near-infrared probes for in vivo detection of amyloid- $\beta$ deposits. J Am Chem Soc 2009; 131: 15257-61.

39 Mataga N, Kaifu Y, Koizumi M. Solvent effects upon fluorescence spectra and the dipole moments of excited molecules. Bull Chem Soc Jpn 1956; 29: 465-70.

40 Lakowicz JR. Principles of fluorescence spectroscopy. 3rd ed. New York: Springer; 2006.

41 Bayliss NS. The effect of the electrostatic polarization of the solvent on electronic absorption spectra in solution. J Chem Phy 1950; 18 : 292-6.

42 Christine G, Gilles U, Laura J, Ben D, Anthony H, Raymond Z.
Synthesis and photophysical properties of borondipyrromethene dyes bearing aryl substituents at the boron center. J Am Chem Soc 2006; 128: 10231-9.

43 Bayliss NS, McRae EG. Solvent effects in organic spectra: dipole forces and the Franck-Condon principle. J Phys Chem 1954; 58 : 1002-6.

44 Kawski A. Solvent-shift effect of electronic spectra and excited state dipole moments. In: Progress in photochemistry and photophysics. New York: CRC Press; 1992. p 1-47.

45 Seliskar CJ, Brand L. Electronic spectra of 2-aminonaphthalene-6sulfonate and related molecules, II: effects of solvent medium on the absorption and fluorescence spectra. J Am Chem Soc 1971; 93: 5414-20.

46 Brand L, Seliskar CJ, Turner DC. The effects of chemical environment on fluorescence probes. In: Chance B, Lee CP, Blasie JK, editors. Probes of structure and function of macromolecules and membranes; Probes and Membrane Function. New York: Academic Press; 1971. p 17-39.

47 Kavarnos GJ. Fundamentals of photoinduced electron transfer. New York: VCH Publishers; 1993.

48 Kavarnos GJ, Turro NJ. Photosensitization by reversible electron transfer: theories, experimental evidence, and examples. Chem Rev 1986; 86: 401-49.

49 Biancalana M, Koide S. Molecular mechanism of Thioflavin-T binding to amyloid fibrils. Biochim Biophys Acta 2010; 1804: 1405-12.

50 Naiki H, Higuchi K, Hosokawa M, Takeda T. Fluorometric determination of amyloid fibrils in vitro using the fluorescent dye, thioflavin $\mathrm{T}$. Anal Biochem 1989; 177: 244-9.

51 Voropai ES, Samtsov MP, Kaplevskii KN, Maskevich AA, Stepuro VI, Povarova OI, et al. Spectral properties of Thioflavin $T$ and its complexes with amyloid fibrils. J Appl Spectrosc 2003; 70: 868-74.

52 Gan C, Zhou L, Zhao Z, Wang H. Benzothiazole Schiff-bases as potential imaging agents for $\beta$-amyloid plaques in Alzheimer's disease. Med Chem Res 2013; 22: 4069-74.

53 Jung SJ, Park YD, Park JH, Yang SD, Hur MG, Yu KH. Synthesis and evaluation of thioflavin-T analogs as potential imaging agents for amyloid plaques. Med Chem Res 2013; 22: 4263-8.

54 Ono M, Hayashi S, Kimura H, Kawashima H, Nakayama M, Saji H. Push-pull benzothiazole derivatives as probes for detecting $\beta$-amyloid plaques in Alzheimer's brains. Bioorg Med Chem 2009; 17: 7002-7.

55 Zhang X, Ran C. Dual functional small molecule probes as fluorophore and ligand for misfolding proteins. Curr Org Chem 2013; 17: 580-93.

56 Hong MC, Kim YK, Choi JY, Yang SQ, Rhee H, Ryu YH, et al. Synthesis and evaluation of stilbene derivatives as a potential imaging agent of amyloid plaques. Bioorg Med Chem 2010; 18: 7724-30.

57 Li Q, Lee JS, Ha C, Park CB, Yang G, Gan WB, et al. Solid-phase synthesis of styryl dyes and their application as amyloid sensors. Angew Chem Int Ed Engl 2004; 43: 6331-5.

58 Li Q, Min J, Ahn YH, Namm J, Kim EM, Lui R, et al. Styryl-based compounds as potential in vivo imaging agents for beta-amyloid plaques. Chembiochem 2007; 8: 1679-87.

59 Park YD, Park JH, Hur MG, Kim SW, Min JJ, Park SH, et al. Fluorescent 2-styrylpyridazin-3(2H)-one derivatives as probes targeting amyloidbeta plaques in Alzheimer's disease. Bioorg Med Chem Lett 2012; 22: 4106-10.

60 Staderini M, Aulić S, Bartolini M, Tran HN, González-Ruiz V, Pérez DI, et al. A fluorescent styrylquinoline with combined therapeutic and diagnostic activities against Alzheimer's and prion diseases. ACS Med Chem Lett 2013; 4: 225-9.

61 Lee YO, Shin JW, Yi C, Lee YH, Sohn NW, Kang C, et al. Detection of $A \beta$ plaques in mouse brain by using a disaggregation-induced 
fluorescence-enhancing probe. Chem Commun 2014; 50: 5741-4.

62 Jung SJ, Park SH, Lee EJ, Park JH, Kong YB, Rho JK, et al. Development of fluorescent probes that bind and stain amyloid plaques in Alzheimer's disease. Arch Pharm Res 2015; 38: 1992-8.

63 Hamaguchi T, Ono K, Yamada M. Review: Curcumin and Alzheimer's disease. CNS Neurosci Ther 2010; 16: 285-97.

64 Yang F, Lim GP, Begum AN, Ubeda OJ, Simmons MR, Ambegaokar $\mathrm{SS}$, et al. Curcumin inhibits formation of amyloid beta oligomers and fibrils, binds plaques, and reduces amyloid in vivo. J Biol Chem 2005; 280: 5892-901.

65 Garcia-Alloza M, Borrelli LA, Rozkalne A, Hyman BT, Bacskai BJ. Curcumin labels amyloid pathology in vivo, disrupts existing plaques, and partially restores distorted neurites in an Alzheimer mouse model. J Neurochem 2007; 102: 1095-104.

66 Zhang X, Tian Y, Li Z, Tian X, Sun H, Liu H, et al. Design and synthesis of curcumin analogues for in vivo fluorescence imaging and inhibiting copper-induced cross-linking of amyloid beta species in Alzheimer's disease. J Am Chem Soc 2013; 135: 16397-409.

67 Giuffrida ML, Caraci F, Pignataro B, Cataldo S, De Bona P, Bruno V, et al. Beta-amyloid monomers are neuroprotective. J Neurosci 2009; 29: 10582-7.

68 Zhang X, Tian Y, Yuan P, Li Y, Yaseen MA, Grutzendler J, et al. A bifunctional curcumin analogue for two-photon imaging and inhibiting crosslinking of amyloid beta in Alzheimer's disease. Chem Commun 2014; 50: 11550-3.

69 Liu K, Guo TL, Chojnacki J, Lee HG, Wang X, Siedlak SL, et al. Bivalent ligand containing curcumin and cholesterol as a fluorescence probe for A $\beta$ plaques in Alzheimer's disease. ACS Chem Neurosci 2012; 3: 141-6.

70 Raymond SB, Skoch J, Hills ID, Nesterov EE, Swager TM, Bacskai BJ. Smart optical probes for near-infrared fluorescence imaging of Alzheimer's disease pathology. Eur J Nucl Med Mol Imaging 2008; 35: S93-8.

71 Okamura N, Mori M, Furumoto S, Yoshikawa T, Harada R, Ito S, et al. In vivo detection of amyloid plaques in the mouse brain using the near-infrared fluorescence probe THK-265. J Alzheimers Dis 2011; 23: $37-48$.

72 Cui M, Ono M, Watanabe H, Kimura H, Liu B, Saji H. Smart nearinfrared fluorescence probes with donor-acceptor structure for in vivo detection of $\beta$-amyloid deposits. J Am Chem Soc 2014; 136 : 3388-94.

73 Fu H, Cui M, Tu P, Pan Z, Liu B. Evaluation of molecules based on the electron donor-acceptor architecture as near-infrared $\beta$-amyloidaltargeting probes. Chem Commun 2014; 50: 11875-8.

74 Kim D, Moon H, Baik SH, Singha S, Jun YW, Wang T, et al. Two-photon absorbing dyes with minimal autofluorescence in tissue imaging: application to in vivo imaging of amyloid- $\beta$ plaques with a negligible background signal. J Am Chem Soc 2015; 137: 6781-9.

75 Ulrich G, Ziessel R, Harriman A. The chemistry of fluorescent bodipy dyes: versatility unsurpassed. Angew Chem Int Ed Engl 2008; 47: 1184-201.

76 Boens N, Leen V, Dehaen W. Fluorescent indicators based on BODIPY. Chem Soc Rev 2012; 41: 1130-72.

77 Parhi AK, Kung MP, PloessI K, Kung HF. Synthesis of fluorescent probes based on stilbenes and diphenylacetylenes targeting $\beta$-amyloid plaques. Tetrahedron Lett 2008; 49: 3395-9.
78 Smith NW, Alonso A, Brown CM, Dzyuba SV. Triazole-containing BODIPY dyes as novel fluorescent probes for soluble oligomers of amyloid Abeta1-42 peptide. Biochem Biophys Res Commun 2010; 391: 1455-8.

79 Ono M, Ishikawa M, Kimura H, Hayashi S, Matsumura K, Watanabe H, et al. Development of dual functional SPECT/fluorescent probes for imaging cerebral beta-amyloid plaques. Bioorg Med Chem Lett 2010; 20: $3885-8$.

80 Ono $\mathrm{M}$, Watanabe $\mathrm{H}$, Kimura $\mathrm{H}$, Saji $\mathrm{H}$. BODIPY-based molecular probe for imaging of cerebral $\beta$-amyloid plaques. ACS Chem Neurosci 2012; 3: 319-24.

81 Watanabe $\mathrm{H}$, Ono M, Matsumura K, Yoshimura M, Kimura H, Saji $H$. Molecular imaging of $\beta$-amyloid plaques with near-infrared boron dipyrromethane (BODIPY)-based fluorescent probes. Mol Imaging 2013; 12: 338-47.

82 Sozmen F, Kolemen S, Kumada HO, Ono M, Saji H, Akkaya EU. Designing BODIPY-based probes for fluorescence imaging of $\beta$-amyloid plaques. RSC Adv 2014; 4: 51032-7.

83 Hintersteiner M, Enz A, Frey P, Jaton AL, Kinzy W, Kneuer R, et al. In vivo detection of amyloid-beta deposits by near-infrared imaging using an oxazine-derivative probe. Nat Biotechnol 2005; 23: 577-83.

84 Gemma S, Colombo L, Forloni G, Savini L, Fracasso C, Caccia S, et al. Pyrroloquinoxaline hydrazones as fluorescent probes for amyloid fibrils. Org Biomol Chem 2011; 9: 5137-48.

85 Munkholm C, Parkinson DR, Walt DR. Intramolecular fluorescence self-quenching of fluoresceinamine. J Am Chem Soc 1990; 112: 2608-12.

86 Carlson JC, Meimetis LG, Hilderbrand SA, Weissleder R. BODIPYtetrazine derivatives as superbright bioorthogonal turn-on probes. Angew Chem Int Ed Engl 2013; 52: 6917-20.

$87 \mathrm{Kim}$ TW, Park JH, Hong Jl. Self-quenching mechanism: the influence of quencher and spacer on quencher-fluorescein probes. Bull Korean Chem Soc 2007; 28: 1221-3.

88 Gabe Y, Urano Y, Kikuchi K, Kojima H, Nagano T. Highly sensitive fluorescence probes for nitric oxide based on boron dipyrromethene chromophore-rational design of potentially useful bioimaging fluorescence probe. J Am Chem Soc 2004; 126: 3357-67.

89 Urano Y, Asanuma D, Hama Y, Koyama Y, Barrett T, Kamiya M, et al. Selective molecular imaging of viable cancer cells with $\mathrm{pH}$-activatable fluorescence probes. Nat Med 2009; 15: 104-9.

90 Ren WM, Xu MM, Liang SH, Xiang HJ, Tang L, Zhang MK, et al. Discovery of a novel fluorescent probe for the sensitive detection of $\beta$-amyloid Deposits. Biosens Bioelectron 2016; 75: 136-41.

91 Klunk WE, Wang Y, Huang GF, Debnath ML, Holt DP, Mathis CA. Uncharged thioflavin-T derivatives bind to amyloid-beta protein with high affinity and readily enter the brain. Life Sci 2001; 69: 1471-84.

92 Marshall MV, Rasmussen JC, Tan IC, Aldrich MB, Adams KE, Wang X, et al. Near-infrared fluorescence imaging in human with indocyanine green: a review and update. Open Surg Oncol J 2010; 2: 12-25.

93 Piper SK, Habermehl C, Schmitz CH, Kuebler WM, Obrig H, Steinbrink $\mathrm{J}$, et al. Towards whole-body fluorescence imaging in humans. PLoS One 2013; 8: e83749.

94 Sevick-Muraca EM. Translation of near-infrared fluorescence imaging technologies: emerging clinical applications. Annu Rev Med 2012; 63: $217-31$. 